\title{
Worldwide research productivity on tramadol: a bibliometric analysis
}

\author{
Waleed M. Sweileh" ${ }^{*}$, Naser Y. Shraim², Sa'ed H. Zyoud ${ }^{3}$ and Samah W. Al-Jabi ${ }^{3}$
}

\begin{abstract}
Background: Pain management and safe use of analgesics is an important medical issue. Tramadol is an old analgesic with controversial properties. Evaluation of worldwide scientific output on tramadol has not been explored. Therefore, the main objective of this study was to give a bibliometric overview of global research productivity on tramadol.

Methods: SciVerse Scopus was used to retrieve and quantitatively and qualitatively analyze worldwide publications on tramadol.

Results: A total of 2059 original and review research articles on tramadol were retrieved from Scopus. Forty-six documents (2.23 \%) were published in Anesthesia and Analgesia Journal whereas 30 (1.46\%) were published in Arzneimittel Forschung Drug Research Journal. Retrieved tramadol documents were published from 71 countries and appeared in 160 peer reviewed journals. Although the United States of America $(259 ; 12.86 \%)$ had the largest contribution to tramadol publications; the contribution by other countries like Turkey $(232 ; 11.27)$ India $(189 ; 8.09 \%)$ and Germany $(176 ; 8.56 \%$ was not far away from that of USA. The most productive institution was Grunenthal, Germany (47; $2.28 \%)$ followed by Tehran University of Medical Sciences, Iran (29; $1.41 \%)$, and, Ortho-McNeil Pharmaceutical Incorporated, USA (25; $1.21 \%)$. Of the 2059 documents, there were 370 documents about dependence. The leading institution in documents pertaining to tramadol dependence was Grunenthal GmbH (18; $4.86 \%)$ followed by Ortho-McNeil Pharmaceutical Incorporated (17; $4.59 \%)$.

Conclusions: The current study showed that there is an obvious interest in tramadol research. More efforts are needed to clarify the abuse potential and safety profile of tramadol to help in determining the legal status of tramadol. Collaboration among pharmaceutical industry, clinical researchers and academic institutions can improve research quantity and quality on tramadol.
\end{abstract}

Keywords: Bibliometric, Tramadol, Scopus, Pain management

\section{Background}

Search for best methods of pain management is as old as mankind (Gildenberg 1997; Greenblatt et al. 1997). However, only in the past several decades did research about pain management showed great momentum and became a cornerstone in the medical field. The initiation of several international peer reviewed journals specialized in the field of pain/anesthesia has contributed to

\footnotetext{
${ }^{*}$ Correspondence: waleedsweileh@yahoo.com;

waleedsweileh@najah.edu

${ }^{1}$ Department of Pharmacology/Toxicology, College of Medicine and Health Sciences, An-Najah National University, Nablus 44839, Palestine

Full list of author information is available at the end of the article
}

this positive momentum in pain research. Furthermore, the discovery and development of potent and unique analgesics have also increased attention to pain research. No doubt that the increase in prevalence of chronic pain has also stimulated many pharmaceutical companies to search for new analgesic medications those bear ideal characteristics. Despite the ongoing research and development in the field of pain, no ideal analgesic drug has been found yet. A study that discussed the characteristics of more than 50 analgesics introduced in the past 50 years concluded that despite intense research efforts, there is no real novel analgesic drug discovery and an ideal analgesic is not yet available (Kissin 2010). In 1977, tramadol, a new and atypical opioid analgesic medication, was 
introduced and marketed by the German pharmaceutical company, Grünenthal GmbH. Since that time, many articles have been published about tramadol and its unique pharmacology and toxicology. Tramadol is unique in that it affects serotonin and norepinephrine systems in addition to its weak $\mu$-opioid receptor agonist activity (Dayer et al. 1994, 1997; Grond and Sablotzki 2004; Epstein et al. 2006; Raffa 2008; Reeves and Burke 2008). Therefore, tramadol has dual mechanism of action; $\mu$ opioid agonist and a serotonin/norepinephrine reuptake inhibitor (Raffa 2013; Vazzana et al. 2015). That is why tramadol causes adverse effects pertaining to elevated brain serotonin levels (serotonin syndrome) especially when coadministered with selective serotonin reuptake inhibitors (SSRI) drug class (Nelson and Philbrick 2012; Beakley et al. 2015). Another important pharmacological aspect of tramadol is its metabolism by CYP2D6 which exhibits wide polymorphism leading to variation in toxic and therapeutic effects of tramadol (Lassen et al. 2015; Ibrahim et al. 2016).

The abuse potential of tramadol is still an ongoing controversy (Friderichs et al. 1978; Murano et al. 1978; Richter et al. 1985; Ehrenreich and Poser 1993; Liu et al. 1999; Aknine et al. 2000; Yates et al. 2001; Brinker et al. 2002; Ripamonti et al. 2004; Naslund and Dahlqvist 2003; Woody et al. 2003; Skipper et al. 2004; Soyka et al. 2004). Understanding progress made in pain management research in general and about tramadol in particular requires periodic assessment of how scientific research in this topic is advancing. Bibliometric analysis, a statistical method for literature evaluation, is commonly used for assessment of research activity in any particular filed (Wallin 2005). Several bibliometric studies on pain related topics have been recently published (Robert et al. 2008a, b; Dubner 2009; Mogil et al. 2009; Onyeka and Chukwuneke 2014). However, based on author's best knowledge, no bibliometric analysis has been published about analgesic drugs, particularly about a controversial medication like tramadol. In this study we planned to give a bibliometric overview of tramadol publications through analysis of temporal research productivity and analysis of highly cited articles in tramadol field. This study is important for those in the field of clinical pharmacology and medicine since it will give them a comprehensive look on current research trends on tramadol and future status of pain management in general and role of tramadol in pain management guidelines.

\section{Methods}

In this study, traditional bibliometric indicators were applied and presented. Such indicators have been explained in previous studies by the same authors. Standard competition ranking (SCR) was used to rank productive journals, countries, authors and institutions. The $h$-index (Hirsch 2005) was used to assess quantity and quality of research productivity by authors, countries and institutions. The journal impact factor (IF) obtained from the Journal Citation Report (JCR; Web of Knowledge) 2014 science edition by Thomson Reuters and the SCImago Journal Rank (SJR) indicator (available at: http://www.scimagojr.com/SCImagoJournalRank.pdf) were used as a quality indicator for journal strength and reputation. The adjustment index (AI) was used to stratify productivity with income and population size and was obtained using the following equation: "AI = [total number of publications for the country/gross domestic product (GDP) per capita of the country] $\times 1000$, where the GDP per capita = GDP/population of the country" (Sweileh et al. 2013; Zyoud et al. 2014e, 2015a). In this study, the keyword entered into Scopus search engine was "tramadol" in the "Article Title". All subject areas were selected and the time interval of the analysis was set up to December 31st, 2013. Analysis was restricted to original and review articles. Citation analysis was completed within 1 day on July 29th, 2015 to avoid bias due to daily in database update. The extracted data were tabulated and analyzed according to the indicators found in previous bibliometric studies (Sweileh et al. 2014; Zyoud et al. 2014b, c, e, f, 2015a, d).

\section{Results}

A total of 2429 research articles on tramadol were retrieved. Of the 2429 articles, there were 1958 (80.61\%) original journal articles, $101(4.16 \%)$ review articles, $146(6.01 \%)$ letters, 67 (2.76 \%) conference papers, and 157 (6.47 \%) other types of publications such as editorial, notes, book chapters, erratum and undefined. Analysis in this manuscript was based on 2059 documents that were original research articles and reviews. The 2059 articles were written in 23 different languages. The main language encountered was English $(\mathrm{n}=1687$; $80.68 \%)$ followed distantly by Turkish $(\mathrm{n}=87 ; 4.16 \%)$, Chinese ( $\mathrm{n}=72 ; 3.44 \%)$, German $(\mathrm{n}=62 ; 2.97 \%)$, Spanish $(\mathrm{n}=56 ; 2.68 \%)$, French $(\mathrm{n}=24 ; 1.15 \%)$, Italian $(\mathrm{n}=21 ; 1.00 \%)$, and 16 other languages $(82 ; 3.92 \%)$. The number of published documents about tramadol in the past 5 years (2008-2013) has increased by approximately 15 -folds compared with the time interval from 1978 to 1988 (Table 1). The first article on tramadol was published in 1978. Retrieved tramadol articles were published from 71 countries and appeared in 160 peer reviewed journals. Top ten productive countries on tramadol research are shown in Table 2. Tramadol research and publications were produced by countries from different world regions and even from countries outside Europe and North America. Although the largest 
Table 1 Worldwide growth of tramadol research activity

\begin{tabular}{llc}
\hline Time interval & $\begin{array}{l}\text { Number of published } \\
\text { documents } \\
\mathbf{N}=\mathbf{2 0 5 9}\end{array}$ & $\%$ \\
\hline $2009-2013$ & 778 & 37.79 \\
$2004-2008$ & 586 & 28.46 \\
$2003-1999$ & 383 & 18.6 \\
$1994-1998$ & 198 & 9.62 \\
$1989-1993$ & 63 & 3.06 \\
$<1989$ & 51 & 2.48 \\
\hline
\end{tabular}

number of articles about tramadol was produced by the USA $(259 ; 12.58 \%)$; the contribution by other countries like Turkey (232; $11.27 \%)$, India (189; $8.09 \%)$ and Germany $(176 ; 8.56 \%)$ was not far away from that of the USA (Table 2). It is noteworthy that Turkey surpassed Germany and other European countries in tramadol research.

The total citations of retrieved articles was 36,275 , with an average of 17.62 citations per article as recorded in Scopus on July 29 th, 2015 . The $h$-index of tramadol publications was 74. List of most commonly cited articles on tramadol is shown in Table 3 (Raffa et al. 1992, 1993; Vickers et al. 1992; Lee et al. 1993; Poulsen et al. 1996; Harati et al. 1998; Sindrup et al. 1999; Scott and Perry 2000; Xia et al. 2000; Grond and Sablotzki 2004). Those about the potential mechanism of action and potential role of tramadol in treatment of neuropathic pain were most commonly cited. Two of the top 10 cited articles were published from the same research group, the Raffa et al., group present in the USA. Table 4 shows top 10 productive journals involved in tramadol research. Fortysix articles (2.24\%) were published in Anesthesia and
Analgesia whereas 30 (1.46\%) were published in Arzneimittel Forschung: Drug Research. Of the top 10 journals, six were in the field of anesthesia and pain, three in the field of pharmacology, therapeutics and drug research and one in the field of clinical pharmacology and anesthesia. Of the top 10 journals, two were Turkish journals while the others were based either in USA or Europe. When the journals were screened for IF, three journals of the top productive ones were not listed in ISI JCR and the remaining were listed and had an IF $<5$.

Table 5 presents scientific subjects of the 2059 articles. As expected, the majority were in the field of medicine (1303; $63.38 \%$ ) followed by pharmacology/toxicology/ pharmaceutics $(721 ; 35.07 \%)$ and chemistry $(189 ; 9.19 \%)$. Of the 2059 documents, there were 370 documents about dependence. The leading institution in documents pertaining to tramadol dependence was Grunenthal $\mathrm{GmbH}$ (18; $4.86 \%)$ followed by Ortho-McNeil Pharmaceutical Incorporated (17; $4.59 \%)$. Table 6 shows top 10 highly productive institutions which published most about tramadol. The most productive institution was Grunenthal, Germany (47; $2.44 \%$ ) followed by Tehran University of Medical Sciences, Iran (25; $1.30 \%)$, and, Ortho-McNeil Pharmaceutical Incorporated, USA (25; $1.3 \%)$. Table 7 presents the top 10 productive authors on about tramadol, along with their affiliations. Half of the top prolific authors were from USA and seven were affiliated with academic institutions.

\section{Discussion}

Evidence-based pain management requires exploration of efficacy and safety of various analgesics as presented in literature. Our study analyzed 2059 research articles retrieved from Scopus, a large databases equipped

Table 2 Top 10 countries in tramadol research

\begin{tabular}{|c|c|c|c|c|c|c|c|c|c|}
\hline $\mathrm{SCR}^{\mathrm{a}}$ & Country & Articles (\%) & Total citation & $\mathrm{H}$-index & $\begin{array}{l}\text { Average } \\
\text { citation }\end{array}$ & $\begin{array}{l}\text { Median } \\
\text { (Q1-Q3) } \\
\text { of citation }\end{array}$ & $\begin{array}{l}\text { Collaborations } \\
\text { with foreign } \\
\text { countries }\end{array}$ & $\begin{array}{l}\text { Number }(\%)^{a} \\
\text { of documents } \\
\text { with interna- } \\
\text { tional authors }\end{array}$ & $\begin{array}{l}\text { Adjustment } \\
\text { index }\end{array}$ \\
\hline $1 \mathrm{st}$ & United States & 259 (12.58) & 9273 & 53 & $19(9-46)$ & 38.44 & 26 & $61(23.55)$ & 4.74 \\
\hline 2nd & Turkey & $232(11.27)$ & 2067 & 24 & $3(1-13)$ & 8.91 & 4 & $8(3.45)$ & 22.00 \\
\hline $3 r d$ & India & 189 (8.09) & 1019 & 16 & $2(0-6)$ & 5.39 & 5 & $8(4.23)$ & 115.85 \\
\hline 4th & Germany & $176(8.56)$ & 5533 & 40 & $17(6-37)$ & 31.44 & 17 & $36(20.45)$ & 3.69 \\
\hline 5 th & China & $134(6.51)$ & 835 & 16 & $2(0-7.25)$ & 6.23 & 4 & $10(7.64)$ & 17.64 \\
\hline 6th & Iran & $101(4.90)$ & 1094 & 18 & $5(2-11.5)$ & 10.83 & 4 & $8(7.92)$ & 19.08 \\
\hline 7th & Italy & $99(4.81)$ & 1609 & 22 & $6(1-11)$ & 7.01 & 15 & $24(24.24)$ & 2.83 \\
\hline 8th & Spain & 80 (3.89) & 1112 & 22 & $8.5(1-24)$ & 13.90 & 14 & $29(36.25)$ & 2.64 \\
\hline 9th & $\begin{array}{l}\text { United King- } \\
\text { dom }\end{array}$ & $64(3.11)$ & 2238 & 26 & $19.5(6.25-41.5)$ & 34.97 & 15 & $24(37.50)$ & 1.40 \\
\hline 10th & France & $50(2.43)$ & 952 & 16 & $9(2-20.25)$ & 19.04 & 13 & $20(40.00)$ & 1.17 \\
\hline
\end{tabular}

a Percentage of documents with international authors from the total number of documents for each country

SCR standard competition ranking, Q1-Q3 lower quartile-upper quartile 
Table 3 Top 10 cited articles in tramadol-related research

\begin{tabular}{lll}
\hline SCR $^{\mathbf{a}}$ & Authors & Journal \\
\hline 1st & Raffa et al. (1992) & Journal of Pharmacology and Experimental Therapeutics \\
2nd & Harati et al. (1998) & Neurology \\
3rd & Grond and Sablotzki (2004) & Clinical Pharmacokinetics \\
4th & Lee et al. (1993) & Drugs \\
5 th & Xia et al. (2000) & Bulletin of Hunan Medical University \\
6th & Scott and Perry (2000) & Drugs \\
7th & Raffa et al. (1993) & Journal of Pharmacology and Experimental Therapeutics \\
8th & Vickers et al. (1992) & Anaesthesia \\
9th & Poulsen et al. (1996) & Clinical Pharmacology and Therapeutics \\
$10 t h$ & Sindrup et al. (1999) & Pain \\
\hline
\end{tabular}

SCR standard competition ranking

${ }^{\text {a }}$ Equal articles have the same ranking number and then a gap is left in the ranking numbers

Table 4 Top 10 journals in which tramadol-related documents were published

\begin{tabular}{|c|c|c|c|c|}
\hline $\mathrm{SCR}^{\mathrm{a}}$ & Journal & $\begin{array}{l}N(\%) \\
N=2059\end{array}$ & IF & SJR \\
\hline $1 s t$ & Anesthesia and Analgesia & $46(2.23)$ & 3.472 & 1.50 \\
\hline 2nd & Arzneimittel Forschung: Drug Research & $30(1.46)$ & 0.701 & 0.25 \\
\hline 2nd & $\begin{array}{l}\text { Agri: The Journal of The Turkish Society of } \\
\text { Algology }\end{array}$ & $30(1.46)$ & N/A & 0.21 \\
\hline 4th & British Journal of Anaesthesia & $28(1.36)$ & 4.853 & 1.84 \\
\hline 4 th & European Journal of Pharmacology & $28(1.36)$ & 2.532 & 0.87 \\
\hline 6th & European Journal of Anaesthesiology & $27(1.31)$ & 2.942 & 0.96 \\
\hline 7th & Paediatric Anaesthesia & 19 (0.92) & 1.850 & 0.84 \\
\hline 7 th & $\begin{array}{l}\text { Journal of Anaesthesiology Clinical } \\
\text { Pharmacology }\end{array}$ & $19(0.92)$ & N/A & 0.30 \\
\hline 9th & Clinical Therapeutics & $18(0.87)$ & 2.731 & 0.80 \\
\hline 9th & $\begin{array}{l}\text { European Journal of Clinical Pharmacol- } \\
\text { ogy }\end{array}$ & $18(0.87)$ & 2.966 & 1.03 \\
\hline 9th & Egyptian Journal of Anaesthesia & $18(0.87)$ & N/A & 0.15 \\
\hline
\end{tabular}

$S C R$ standard competition ranking, IF impact factor, SJR standard journal ranking, $N / A$ not available

${ }^{a}$ Equal journals have the same ranking number and then a gap is left in the ranking numbers

with search options that facilitate citation and comparative analysis (de Granda-Orive et al. 2011). Scopus covers higher number of journals in different subject areas and allows citation analysis which made it very suitable for bibliometric analysis compared to other databases (Tadmouri and Bissar-Tadmouri 2004; Falagas et al. 2008; Kulkarni et al. 2009; de Granda-Orive et al. 2011).

Tramadol was developed in early 1960s by Grunenthal, a German pharmaceutical company. Tramadol entered the West German market in late 1970s with the trade name Tramal ${ }^{\circledR}$. Approximately 20 years later, tramadol was introduced to the US market. Currently, tramadol is available in 100 countries under different trade names.
Table 5 Top 10 subject fields in tramadol-related documents

\begin{tabular}{llc}
\hline SCR $^{\mathbf{a}}$ & Subject area & $\mathbf{N}(\mathbf{\%})^{\mathbf{b}}$ \\
& & $\mathbf{N = 2 0 5 9}$ \\
\hline 1st & Medicine & $1303(63.38)$ \\
2nd & Pharmacology, toxicology and pharmaceutics & $721(35.02)$ \\
2nd & Chemistry & $189(9.18)$ \\
4th & Biochemistry, genetics and molecular biology & $177(8.60)$ \\
5th & Neuroscience & $132(6.41)$ \\
6th & Veterinary & $119(5.78)$ \\
7th & Environmental science & $46(2.23)$ \\
8th & Psychology & $42(2.04)$ \\
9th & Agricultural and biological sciences & $30(1.46)$ \\
9th & Dentistry & $30(1.46)$ \\
9th & Nursing & $30(1.46)$
\end{tabular}

SCR standard competition ranking, USA United States of America

${ }^{a}$ Equal research areas have the same ranking number and then a gap is left in the ranking numbers

b The total \% exceeds $100 \%$ because of overlap among subjects

Although tramadol is unique in having dual mechanism of action, its introduction to the worldwide market was slow and cautious. A possible reason for this slow introduction was the uncertainty regarding safety and abuse potential. However, reports and clinical trials have shown that tramadol has lesser toxic profile and better tolerability than oral traditional nonsteroidal anti-inflammatory drugs (NSAIDs) or commonly used opioids (Preston et al. 1991; Adams et al. 2006; Epstein et al. 2006). A study carried out to compare the abuse potential among NSAIDs, codeine, placebo and tramadol has found that abuse potential for tramadol is significantly lower than that of codeine (Adams et al. 2006). On the other hand, reports about other serious side effects like seizure have been reported (Tobias 1997; Raffa and Stone 2008; Sen 
Table 6 Top 10 productive institution in tramadol-related research

\begin{tabular}{llll}
\hline $\mathbf{S C R}^{\mathbf{a}}$ & Institute & $\begin{array}{l}\mathbf{N} \text { (\%) } \\
\mathbf{N = 2 0 5 9}(\mathbf{1 0 0} \mathbf{0})\end{array}$ & Affiliation of the institute \\
\hline 1st & Grunenthal GmbH & $47(2.28)$ & Germany \\
2nd & Tehran University of Medical Sciences & $29(1.41)$ & Iran \\
3rd & Ortho-McNeil Pharmaceutical Incorporated & $25(1.21)$ & USA \\
4th & Çukurova Üniversitesi & $24(1.17)$ & Turkey \\
5th & R.W. Johnson Pharmaceutical Research Institute & $17(0.83)$ & USA \\
6th & Universidade de Sao Paulo & $16(0.78)$ & Brazil \\
7th & University of Tennessee, Knoxville & $13(0.63)$ & USA \\
8th & Universität Bonn & $12(0.58)$ & Germany \\
8th & Università degli Studi di Roma La Sapienza & $12(0.58)$ & Italy \\
8th & Poznan University of Medical Sciences & $12(0.58)$ & Poland \\
8th & Bethune International Peace Hospital of the PLA & $12(0.58)$ & China
\end{tabular}

SCR standard competition ranking, USA United States of America

${ }^{a}$ Equal institutions have the same ranking number and then a gap is left in the ranking numbers

Table 7 Top 10 authors in tramadol research

\begin{tabular}{|c|c|c|c|c|}
\hline$S_{C R}{ }^{a}$ & Author name & Total number of articles & Affiliation & Country \\
\hline 1 st & R. B. Raffa & 18 & Temple University, School of Pharmacy, Philadelphia & USA \\
\hline 2nd & M. Giorgi & 16 & University of Pisa, Department of Veterinary Clinical Sciences, Pisa & Italy \\
\hline 3rd & M. Kamin & 15 & Ortho Biotech Products, L.P., Bridgewater & USA \\
\hline $3 \mathrm{rd}$ & N. R. Rosenthal & 15 & Ortho-McNeil Pharmaceutical Incorporated, Raritan & USA \\
\hline 5th & S. K. Cox & 14 & $\begin{array}{l}\text { University of Tennessee, Knoxville, Department of Biomedical and Diagnostic Sciences, } \\
\text { Knoxville }\end{array}$ & USA \\
\hline 6th & Y. Gunes & 13 & Cukurova University, Department of Anesthesiology, Adana & Turkey \\
\hline 6th & D. Jordan & 13 & Ortho-McNeil Pharmaceutical Incorporated, Raritan & USA \\
\hline 6th & D. Ozcengiz & 13 & Cukurova University, Department of Anesthesiology, Adana & Turkey \\
\hline 9th & G. Saccomanni & 12 & Universita di Pisa, Dipartimento di Farmacia, Pisa & Italy \\
\hline 9th & K. Minami & 12 & Emergency Life-Saving Technique Academy of Tokyo, Hachioji & Japan \\
\hline 9th & G. Isik & 12 & Çukurova University, Faculty of Medicine, Department of Anesthesiology, Adana & Turkey \\
\hline
\end{tabular}

SCR standard competition ranking, USA United States of America

a Equal authors have the same ranking number and then a gap is left in the ranking numbers

et al. 2009; Singh et al. 2009; Talaie et al. 2009; Taghaddosinejad et al. 2011; Yarkan Uysal et al. 2011; Boostani and Derakhshan 2012; Mehrpour 2013).

In our study, bibliometric techniques were applied to give an overview on worldwide published research on tramadol. The first publication about tramadol appeared in 1978 followed by rapid increase, particularly after 1995 which coincide with the year of introduction in the US market. The first article about tramadol as analgesic was published by Rost, A., Schenck, E.G. in Arzneimittel-Forschung/Drug Research in 1978 as a comparative clinical study (Rost and Schenck 1978). The discovery and identification of tramadol and its unique mechanism of action lead to the development of a newer tramadollike agent named tapentadol which is currently available in the market and promoted to have better safety profile than tramadol (Giorgi et al. 2012; Mercadante et al. 2012, 2013; Cepeda et al. 2013; Gohler et al. 2013; Lee et al. 2013; Schwittay et al. 2013; Singh et al. 2013; Fejos et al. 2014).

An average of 17.62 (median $=6$ ) citations per article was obtained in this study. This finding means that tramadol is an interesting topic for scientific research community. Furthermore, the fact that the top 10 productive countries and top 10 productive institutions in tramadol research included countries and institutes outside the Americas and Europe suggest that tramadol research is of interest to many nations. It was obvious that non-academic institutions, particularly pharmaceutical companies, were involved heavily in tramadol 
research for human or veterinary use (Wu et al. 2001; Teppema et al. 2003; Giorgi et al. 2009a, b). In addition, research about tramadol and its potential use in premature ejaculation gave further momentum to tramadol research (Safarinejad and Hosseini 2006; Salem et al. 2008; Bar-Or et al. 2012). At the official level, research interest in tramadol was motivated by the debate about the legal status and whether to schedule or un-schedule tramadol. In Sweden and in several states in the USA, including New York, Arkansas, Illinois, Kentucky, Mississippi, North Dakota, Oklahoma, Tennessee, Wyoming, and West Virginia have categorized tramadol as a schedule IV controlled substance. In most countries of the world, the legal status of tramadol is currently under re-evaluation.

Finally, the authors believe that this study, like all other bibliometric studies, has few limitations that have been explained in previous bibliometric studies (Li et al. 2011; Sweileh et al. 2013; Zyoud et al. 2014a, d, 2015b, c; Zyoud 2015). Such limitations include the use of Scopus database; the use of "tramadol" word as a title keyword in the search engine; and the restriction of analysis to original articles and article reviews. However, despite all this, the current study will be of great value for people in pain management policy and those involved in research pertaining to analgesia.

\section{Conclusions}

Tramadol is an analgesic with controversial properties which made it an appealing topic for researchers from different scientific disciplines. Research output about tramadol was not confined to particular country. More research efforts are needed to shed light on the abuse potential and the non-analgesic therapeutic benefits of tramadol. Research activity about tramadol needs to be directed toward minimizing its side effects. Such research activity can be achieved through collaboration among people in pharmaceutical industry, clinical practice and academic institutions.

\section{Authors' contributions}

All authors were involved in drafting the article, and all authors approved the final version to be submitted for publication. All authors read and approved the final manuscript.

\section{Author details}

${ }^{1}$ Department of Pharmacology/Toxicology, College of Medicine and Health Sciences, An-Najah National University, Nablus 44839, Palestine. ${ }^{2}$ Department of Pharmaceutical Chemistry and Technology, College of Medicine and Health Sciences, An-Najah National University, Nablus 44839, Palestine. ${ }^{3}$ Department of Clinical and Community Pharmacy, College of Medicine and Health Sciences, An-Najah National University, Nablus 44839, Palestine.

\section{Acknowledgements}

The authors would like to thank An-Najah National University for giving the opportunities to access most recent information sources such as Scopus database.

\section{Competing interests}

The authors declare that they have no competing interests.

Received: 31 October 2015 Accepted: 8 July 2016

Published online: 19 July 2016

References

Adams EH, Breiner S, Cicero TJ, Geller A, Inciardi JA, Schnoll SH, Senay EC, Woody GE (2006) A comparison of the abuse liability of tramadol, NSAIDs, and hydrocodone in patients with chronic pain. J Pain Symptom Manage 31(5):465-476

Aknine X, Varescon-Pousson I, Boissonnas A (2000) Tramadol dependence in a previous heroin addict. Ann Med Interne 151(Suppl. B):B34-B35

Bar-Or D, Salottolo KM, Orlando A, Winkler JV (2012) A randomized doubleblind, placebo-controlled multicenter study to evaluate the efficacy and safety of two doses of the tramadol orally disintegrating tablet for the treatment of premature ejaculation within less than 2 minutes. Eur Urol 61(4):736-743

Beakley BD, Kaye AM, Kaye AD (2015) Tramadol, pharmacology, side effects, and serotonin syndrome: a review. Pain Physician 18(4):395-400

Boostani R, Derakhshan S (2012) Tramadol induced seizure: a 3-year study. Casp J Intern Med 3(3):484-487

Brinker A, Bonnel RA, Beitz J (2002) Abuse, dependence, or withdrawal associated with tramadol. Am J Psychiatry 159(5):881 (author reply 881-882)

Cepeda MS, Fife D, Ma Q, Ryan PB (2013) Comparison of the risks of opioid abuse or dependence between tapentadol and oxycodone: results from a cohort study. J Pain 14(10):1227-1241

Dayer P, Collart L, Desmeules J (1994) The pharmacology of tramadol. Drugs 47(Suppl. 1):3-7

Dayer P, Desmeules J, Collart L (1997) Pharmacology of tramadol. Drugs 53(Suppl. 2):18-24

de Granda-Orive Jl, Alonso-Arroyo A, Roig-Vazquez F (2011) Which data base should we use for our literature analysis? Web of Science versus SCOPUS. Arch Bronconeumol 47(4):213

Dubner R (2009) A bibliometric analysis of the pain journal as a representation of progress and trends in the field. Pain 142(1-2):9-10

Ehrenreich H, Poser W (1993) Dependence on tramadol. Clin Investig 72(1):76

Epstein DH, Preston KL, Jasinski DR (2006) Abuse liability, behavioral pharmacology, and physical-dependence potential of opioids in humans and laboratory animals: lessons from tramadol. Biol Psychol 73(1):90-99

Falagas ME, Pitsouni El, Malietzis GA, Pappas G (2008) Comparison of PubMed, scopus, web of science, and google scholar: strengths and weaknesses. FASEB J 22(2):338-342

Fejos I, He Y, Volgyi G, Kazsoki A, Sun J, Chen W, Sohajda T, Szente L, Jiang X, Beni S (2014) Tapentadol enantiomers: synthesis, physico-chemical characterization and cyclodextrin interactions. J Pharm Biomed Anal 88:594-601

Friderichs E, Felgenhauer F, Jongschaap P, Osterloh G (1978) Pharmacological studies on analgesia, dependence on and tolerance of tramadol, a potent analgetic drug (author's transl). Arzneimittelforschung 28(1a):122-134

Gildenberg PL (1997) History of pain management. In: Greenblatt SH, Dagi TF, Epstein MH (eds) A history of neurosurgery. American Association of Neurological Surgeons, Park Ridge, pp 439-464

Giorgi M, Del Carlo S, Saccomanni G, Lebkowska-Wieruszewska B, Turini V, Kowalski C (2009a) Biopharmaceutical profile of tramadol in the dog. Vet Res Commun 33(Suppl. 1):189-192

Giorgi M, Saccomanni G, Lebkowska-Wieruszewska B, Kowalski C (2009b) Pharmacokinetic evaluation of tramadol and its major metabolites after single oral sustained tablet administration in the dog: a pilot study. Vet J 180(2):253-255

Giorgi M, Meizler A, Mills PC (2012) Pharmacokinetics of the novel atypical opioid tapentadol following oral and intravenous administration in dogs. Vet J 194(3):309-313

Gohler K, Brett M, Smit JW, Rengelshausen J, Terlinden R (2013) Comparative pharmacokinetics and bioavailability of tapentadol following oral administration of immediate- and prolonged-release formulations. Int J Clin Pharmacol Ther 51(4):338-348 
Greenblatt SH, Dagi TF, Epstein MH (1997) A history of neurosurgery: in its scientific and professional contexts. The American Association of Neurological Surgeons, Park Ridge

Grond S, Sablotzki A (2004) Clinical pharmacology of tramadol. Clin Pharmacokinet 43(13):879-923

Harati Y, Gooch C, Swenson M, Edelman S, Greene D, Raskin P, Donofrio P, Cornblath D, Sachdeo R, Siu CO, Kamin M (1998) Double-blind randomized trial of tramadol for the treatment of the pain of diabetic neuropathy. Neurology 50(6):1842-1846

Hirsch JE (2005) An index to quantify an individual's scientific research output. Proc Natl Acad Sci USA 102(46):16569-16572

Ibrahim SF, Ali MM, Gouda AS, Rashed LA (2016) Association between the severity of tramadol toxicity and some CYP2D6 allelic variants in Egyptian tramadol intoxicated patients. Emerg Med 6:303

Kissin I (2010) The development of new analgesics over the past 50 years: a lack of real breakthrough drugs. Anesth Analg 110(3):780-789

Kulkarni AV, Aziz B, Shams I, Busse JW (2009) Comparisons of citations in Web of science, scopus, and google scholar for articles published in general medical journals. JAMA 302(10):1092-1096

Lassen D, Damkier P, Brosen K (2015) The pharmacogenetics of tramadol. Clin Pharmacokinet 54(8):825-836

Lee CR, McTavish D, Sorkin EM (1993) Tramadol. A preliminary review of its pharmacodynamic and pharmacokinetic properties, and therapeutic potential in acute and chronic pain states. Drugs 46(2):313-340

Lee HK, Lebkowska-Wieruszewska B, Kim TW, Kowaski CJ, Giorgi M (2013) Pharmacokinetics of the novel atypical opioid tapentadol after intravenous, intramuscular and subcutaneous administration in cats. Vet J 198(3):620-624

Li XQ, Tao KM, Zhou QH, Ling CQ (2011) Scientific publications from mainland China, Taiwan, and Hong Kong in integrative and complementary medicine journals: a ten-year literature survey. Am J Chin Med 39(4):639-649

Liu ZM, Zhou WH, Lian Z, Mu Y, Ren ZH, Cao JQ, Cai ZJ (1999) Drug dependence and abuse potential of tramadol. Zhongguo Yao Li Xue Bao 20(1):52-54

Mehrpour O (2013) Addiction and seizure ability of tramadol in high-risk patients. Indian J Anaesth 57(1):86-87

Mercadante S, Porzio G, Ferrera P, Aielli F, Adile C, Ficorella C, Giarratano A, Casuccio A (2012) Tapentadol in cancer pain management: a prospective open-label study. Curr Med Res Opin 28(11):1775-1779

Mercadante S, Porzio G, Aielli F, Adile C, Verna L, Ficorella C, Giarratano A, Casuccio A (2013) Opioid switching from and to tapentadol extended release in cancer patients: conversion ratio with other opioids. Curr Med Res Opin 29(6):661-666

Mogil JS, Simmonds K, Simmonds MJ (2009) Pain research from 1975 to 2007: a categorical and bibliometric meta-trend analysis of every research paper published in the journal, Pain. Pain 142(1-2):48-58

Murano T, Yamamoto H, Endo N, Kudo Y, Okada N, Masuda Y, Yano I (1978) Studies on dependence on tramadol in rats. Arzneimittelforschung 28(1a):152-158

Naslund S, Dahlqvist R (2003) Treatment with tramadol can give rise to dependence and abuse. Lakartidningen 100(9):712-714

Nelson EM, Philbrick AM (2012) Avoiding serotonin syndrome: the nature of the interaction between tramadol and selective serotonin reuptake inhibitors. Ann Pharmacother 46(12):1712-1716

Onyeka TC, Chukwuneke FN (2014) Pain research in Africa: a ten-year bibliometric survey. J Anesth 28(4):511-516

Poulsen L, Arendt-Nielsen L, Brosen K, Sindrup SH (1996) The hypoalgesic effect of tramadol in relation to CYP2D6. Clin Pharmacol Ther 60(6):636-644

Preston KL, Jasinski DR, Testa M (1991) Abuse potential and pharmacological comparison of tramadol and morphine. Drug Alcohol Depend 27(1):7-17

Raffa RB (2008) Basic pharmacology relevant to drug abuse assessment: tramadol as example. J Clin Pharm Ther 33(2):101-108

Raffa RB (2013) Drugs with mixed action and combinations: emphasis on tramadol. In: Gebhart GF, Schmidt RF (eds) Encyclopaedia of pain. Springer, Berlin, Heidelberg, pp 1071-1075

Raffa RB, Stone DJ Jr (2008) Unexceptional seizure potential of tramadol or its enantiomers or metabolites in mice. J Pharmacol Exp Ther 325(2):500-506

Raffa RB, Friderichs E, Reimann W, Shank RP, Codd EE, Vaught JL (1992) Opioid and nonopioid components independently contribute to the mechanism of action of tramadol, an 'atypical'opioid analgesic. J Pharmacol Exp Ther 260(1):275-285

Raffa RB, Friderichs E, Reimann W, Shank RP, Codd EE, Vaught JL, Jacoby HI, Selve N (1993) Complementary and synergistic antinociceptive interaction between the enantiomers of tramadol. J Pharmacol Exp Ther 267(1):331-340

Reeves RR, Burke RS (2008) Tramadol: basic pharmacology and emerging concepts. Drugs Today 44(11):827-836

Richter W, Barth H, Flohe L, Giertz H (1985) Clinical investigation on the development of dependence during oral therapy with tramadol. Arzneimittelforschung 35(11):1742-1744

Ripamonti C, Fagnoni E, De Conno F (2004) Withdrawal syndrome after delayed tramadol intake. Am J Psychiatry 161(12):2326-2327

Robert C, Caillieux N, Wilson CS, Gaudy JF, Arreto CD (2008a) World orofacial pain research production: a bibliometric study (2004-2005). J Orofac Pain 22(3):181-189

Robert C, Wilson CS, Donnadieu S, Gaudy JF, Arreto CD (2008b) Bibliometric analysis of the scientific literature on pain research: a 2006 study. Pain 138(2):250-254

Rost A, Schenck EG (1978) The effect of tramadol and other analgesics on the pain threshold in human dental pulp (author's transl). Arzneimittelforschung 28(1a):181-183

Safarinejad MR, Hosseini SY (2006) Safety and efficacy of tramadol in the treatment of premature ejaculation: a double-blind, placebo-controlled, fixed-dose, randomized study. J Clin Psychopharmacol 26(1):27-31

Salem EA, Wilson SK, Bissada NK, Delk JR, Hellstrom WJ, Cleves MA (2008) Tramadol HCL has promise in on-demand use to treat premature ejaculation. J Sex Med 5(1):188-193

Schwittay A, Schumann C, Litzenburger BC, Schwenke K (2013) Tapentadol prolonged release for severe chronic pain: results of a noninterventional study involving general practitioners and internists. J Pain Palliat Care Pharmacother 27(3):225-234

Scott LJ, Perry CM (2000) Tramadol: a review of its use in perioperative pain. Drugs 60(1):139-176

Sen H, Ozkan S, Dagli G (2009) Epileptic seizure during patient-controlled analgesia with tramadol. Eur J Anaesthesiol 26(5):447

Sindrup SH, Andersen G, Madsen C, Smith T, Brosen K, Jensen TS (1999) Tramadol relieves pain and allodynia in polyneuropathy: a randomised, double-blind, controlled trial. Pain 83(1):85-90

Singh NK, Haleem S, Gupta V, Ansari MM, Khan AQ, Moh DM (2009) Tramadol induced seizure. Is isoniazid the culprit? Neurosciences 14(3):294-295

Singh DR, Nag K, Shetti AN, Krishnaveni N (2013) Tapentadol hydrochloride: a novel analgesic. Saudi J Anaesth 7(3):322-326

Skipper GE, Fletcher C, Rocha-Judd R, Brase D (2004) Tramadol abuse and dependence among physicians. JAMA 292(15):1818-1819

Soyka M, Backmund M, Hasemann S (2004) Tramadol use and dependence in chronic noncancer pain patients. Pharmacopsychiatry 37(4):191-192

Sweileh WM, Zyoud SH, Sawalha AF, Abu-Taha A, Hussein A, Al-Jabi SW (2013) Medical and biomedical research productivity from Palestine, 2002-2011. BMC Res Notes 6:41

Sweileh WM, Zyoud SH, Al-Jabi SW, Sawalha AF (2014) Substance use disorders in Arab countries: research activity and bibliometric analysis. Subst Abuse Treat Prev Policy 9:33

Tadmouri GO, Bissar-Tadmouri N (2004) A major pitfall in the search strategy on PubMed. Saudi Med J 25(1):7-10

Taghaddosinejad F, Mehrpour O, Afshari R, Seghatoleslami A, Abdollahi M, Dart RC (2011) Factors related to seizure in tramadol poisoning and its blood concentration. J Med Toxicol 7(3):183-188

Talaie H, Panahandeh R, Fayaznouri M, Asadi Z, Abdollahi M (2009) Doseindependent occurrence of seizure with tramadol. J Med Toxicol 5(2):63-67

Teppema LJ, Nieuwenhuijs D, Olievier CN, Dahan A (2003) Respiratory depression by tramadol in the cat: involvement of opioid receptors. Anesthesiology 98(2):420-427

Tobias JD (1997) Seizure after overdose of tramadol. South Med J 90(8):826-827

Vazzana M, Andreani T, Fangueiro J, Faggio C, Silva C, Santini A, Garcia ML, Silva AM, Souto EB (2015) Tramadol hydrochloride: pharmacokinetics, pharmacodynamics, adverse side effects, co-administration of drugs and new drug delivery systems. Biomed Pharmacother 70:234-238 
Vickers M, O'flaherty D, Szekely S, Read M, Yoshizumi J (1992) Tramadol: pain relief by an opioid without depression of respiration. Anaesthesia 47(4):291-296

Wallin JA (2005) Bibliometric methods: pitfalls and possibilities. Basic Clin Pharmacol Toxicol 97(5):261-275

Woody GE, Senay EC, Geller A, Adams EH, Inciardi JA, Schnoll S, Munoz A, Cicero TJ (2003) An independent assessment of MEDWatch reporting for abuse/dependence and withdrawal from Ultram (tramadol hydrochloride). Drug Alcohol Depend 72(2):163-168

Wu WN, McKown LA, Gauthier AD, Jones WJ, Raffa RB (2001) Metabolism of the analgesic drug, tramadol hydrochloride, in rat and dog. Xenobiotica 31(7):423-441

Xia SL, Luo JG, Tan HY (2000) Analgesic effect of tramadol in the treatment of pulpitis. Hunan Yi Ke Da Xue Xue Bao 25(4):350-360

Yarkan Uysal H, Bilimgut B, Dikmen B, Inan N, Ulger G, Eruyar S (2011) Epileptic seizure following IV tramadol in a patient with mental retardation and cerebellar ataxia. Pain Med 12(5):833-836

Yates WR, Nguyen MH, Warnock JK (2001) Tramadol dependence with no history of substance abuse. Am J Psychiatry 158(6):964

Zyoud SH (2015) Bibliometric analysis on global Catha edulis (khat) research production during the period of 1952-2014. Glob Health 11:39

Zyoud SH, Al-Jabi S, Sweileh W, Awang R (2014a) A bibliometric analysis of research productivity of Malaysian publications in leading toxicology journals during a 10-year period (2003-2012). Hum Exp Toxicol 33(12):1284-1293

Zyoud SH, Al-Jabi SW, Sweileh WM (2014b) Bibliometric analysis of scientific publications on waterpipe (narghile, shisha, hookah) tobacco smoking during the period 2003-2012. Tob Induc Dis 12(1):7
Zyoud SH, Al-Jabi SW, Sweileh WM (2014c) Worldwide research productivity in the field of electronic cigarette: a bibliometric analysis. BMC Public Health 14(1):667

Zyoud SH, Al-Jabi SW, Sweileh WM, Awang R (2014d) Assessing the scientific research productivity of a leading toxicology journal: a case study of human \& experimental toxicology from 2003 to 2012. SAGE Open Med 2:2050312114523424

Zyoud SH, Al-Jabi SW, Sweileh WM, Awang R (2014e) A bibliometric analysis of toxicology research productivity in Middle Eastern Arab countries during a 10-year period (2003-2012). Health Res Policy Syst 12(1):4

Zyoud SH, Al-Jabi SW, Sweileh WM, Awang R (2014f) A scopus-based examination of tobacco use publications in Middle Eastern Arab countries during the period 2003-2012. Harm Reduct J 11(1):14

Zyoud SH, Al-Jabi SW, Sweileh WM (2015a) Worldwide research productivity of paracetamol (acetaminophen) poisoning: a bibliometric analysis (2003-2012). Hum Exp Toxicol 34(1):12-23

Zyoud SH, Al-Jabi SW, Sweileh WM, Al-Khalil S, Alqub M, Awang R (2015b) Global methaemoglobinaemia research output (1940-2013): a bibliometric analysis. Springerplus 4:626

Zyoud SH, Al-Jabi SW, Sweileh WM, Al-Khalil S, Sawalha AF, Awang R (2015c) The Arab world's contribution to solid waste literature: a bibliometric analysis. J Occup Med Toxicol 10:35

Zyoud SH, Al-Jabi SW, Sweileh WM, Waring WS (2015d) Scientific research related to calcium channel blockers poisoning: bibliometric analysis in Scopus, 1968-2012. Hum Exp Toxicol 34(11):1162-1170

\section{Submit your manuscript to a SpringerOpen ${ }^{\circ}$ journal and benefit from:}

- Convenient online submission

- Rigorous peer review

- Immediate publication on acceptance

- Open access: articles freely available online

- High visibility within the field

- Retaining the copyright to your article

Submit your next manuscript at springeropen.com 